\section{Acknowledgements}

I would like to acknowledge the kind help of Dr L. Vati, Bryn-y-Neuadd Hospital, and Professor Greg Wilkinson, London Hospital Medical College.

\section{References}

Duker, P., Van Druenen, C., Jol, K. \& Oud, H. (1986) Determinants of maladaptive behaviour of institutionalized mentally retarded individuals. American Journal of Mental Deficiency, 91, 51-56.
Espie, C., Pashley, A., Bonham, K. et al (1989) The mentally handicapped person with epilepsy: a comparative study investigating psychosocial functioning. Journal of Mental Deficiency Research, 33, 123-135.

FischBACHER, E. (1982) Effect of reduction of anticonvulsants on wellbeing. British Medical Journal, 285, 423-424.

LUND, J. (1985) Epilepsy and psychiatric disorder in the mentally retarded adult. Acta Psychiatrica Scandinavica, 72, 557-562.

\title{
Will the information recorded in psychiatric notes change when patients have the right to read them?
}

\author{
RuPERT MCShane, Senior House Officer; DeRmot Rowe, Senior House Officer; and \\ DAVID JULIER, Consultant Psychiatrist, Littlemore Hospital Oxford OX4 4XN
}

Psychiatric patients have had the right to see their notes from 1 November 1991. The 'Access to Health Records Act (1990)' makes provision for certain parts of the record to be exempt, including information which may cause serious mental or physical harm to the patient or anyone else. In addition, patients should not have access to information given by third party informants unless appropriate consent has been obtained. The legislation only applies to records made after 1 November 1991. It does not cover informal arrangements where written application for access is not made.

Several studies have suggested that access to notes may have therapeutic potential for the patient (e.g. Parrott et al, 1988). Patients are more likely to ask to see their notes if they are informed of their right to do so. Nevertheless, worries remain that health care workers and informants will become less than frank in the information which they record or volunteer.

\section{The study and findings}

A postal survey of all GPs, hospital psychiatric doctors and psychiatric nurses in the Oxford District was conducted between 1 June and 15 July 1991.

Questionnaires were sent to 272 GPs, 49 consultant and junior hospital psychiatrists, and 83 qualified RMNs. After a follow-up message to nonresponders the response rates were $83 \%$ from GPs, $90 \%$ from hospital doctors, and $77 \%$ from nurses.

The questionnaire investigated three issues.

(a) If psychiatric patients were routinely informed of their right to see their hospital notes, how inhibited would you have felt about recording an opinion about the personality of the last (in)patient who was referred to/by you?

(b) How important do you think it is that you are told if a psychiatric in-patient is going to see 
their hospital notes which were written after the introduction of the new law, including letters/entries from yourself?

(c) How likely is it that, over the next five years, you would suffer serious physical or mental harm as a result of patients being allowed to see their hospital notes, assuming they had access to all their old notes?

The replies to question one were as follows (percentages in brackets):

\begin{tabular}{lccccc}
\hline & $\begin{array}{c}\text { Not at all } \\
\text { inhibited }\end{array}$ & $\begin{array}{c}\text { Slightly } \\
\text { inhibited }\end{array}$ & $\begin{array}{c}\text { Moderately } \\
\text { inhibited }\end{array}$ & $\begin{array}{c}\text { Very } \\
\text { inhibited }\end{array}$ & $\begin{array}{c}\text { Extremely } \\
\text { inhibited }\end{array}$ \\
\hline GPs & $21(10)$ & $52(25)$ & $72(34)$ & $51(24)$ & $17(8)$ \\
Hospital psychiatrists & $5(12)$ & $18(43)$ & $13(31)$ & $5(12)$ & $1(2)$ \\
RMNs & $12(22)$ & $20(36)$ & $16(29)$ & $7(13)$ & $0(0)$ \\
\hline
\end{tabular}

Only $81(26 \%)$ of all respondents said they would be 'very' or 'extremely' inhibited from recording opinions about a patient's personality. However, general practitioners were significantly more likely (chi-square test, $P<0.001$ ), to fall into these categories than psychiatric doctors and nurses (who did not differ in their responses). We did not investigate the attitude of hospital doctors towards patients seeing their notes in a general practice setting.

There was a striking uniformity between the three groups in the desire to be informed if patients were to read letters or entries in the notes which they had written. About $\mathbf{4 0 \%}$ of each group thought it was 'very' or 'extremely' important that they were consulted in this eventuality, while only $25 \%$ thought it 'not at all' or 'slightly' important.

The highest levels of concern about suffering some form of recrimination as a result of patients seeing their notes were expressed more commonly by nursing than medical staff: $11 \%$ of nurses thought it 'very' or 'extremely likely' that they would suffer serious mental or physical harm as a result of patients having access to their notes, assuming they had access to all their old notes.

There were significant $(P=0.0001)$ but weak $(r=$ 0.38 to $r=0.51$, Spearman rho rank) correlations between the three questions, which may reflect a core underlying attitude such as 'cautiousness' towards the issue.

\section{Comment}

The response rate to this postal survey would seem to indicate the high level of interest in the subject among those caring for psychiatric patients. This was also reflected in the large number of comments written on the question papers, particularly by GPs.

Two important problems arise from a general right of access to psychiatric notes. Firstly, the notes often contain information from relatives and associates of patients. Such information may be less freely volunteered if informants have the perception that patients may later see it written in their notes. On this basis the Royal College of Psychiatrists (Priest, 1986) recommended against the legislation of a general right of access, preferring instead the existing informal arrangements. However, the Act is now with us and we shall have to develop systems to enable access to third party information to be limited as the law demands.

Secondly, the usefulness of psychiatric notes may be diminished if subjective opinions and speculation are censored before reaching the page. The BMA advises, "Personal views about the patient's behaviour or temperament should not be included unless these have a potential bearing on treatment". In psychiatry they clearly do.

The BMA (1990) also advises, "Psychiatrists and GPs (should) liaise before extracts from psychiatric records are released". This preliminary study reinforces this message and suggests that nurses would like to be informed as well. It also raises the possibility that such interdisciplinary communication may be important if professionals are to feel sufficiently confident to express subjective opinions.

\section{References}

Access to Health Records Act 1990: London: HMSO.

BMA Professional Division (1990) Guidelines on the Access to Health Records Act 1990. Guidance Note Ethics. No. 1. November 1990.

Parrott, J., Strathdee, G. \& Brown, P. (1988) Patient access to psychiatric records: the patients' view. Journal of the Royal Society of Medicine, 81, 520-522.

PrIEst, R. G. (1986) Data Protection Act: Subject access to personal health information (DA 8523): DHSS consultation paper. Bulletin of the Royal College of Psychiatrists, 10, 185. 